\title{
Zonguldak Metropolitan Alanındaki Arazi Kullanımı Arazi Örtüsünün Yer Yüzey Sıcaklığına Etkisi
}

\author{
Ali İhsan ŞEKERTEKİN ${ }^{1 *}$, Aycan Murat MARANGOZ ${ }^{2}$ \\ ${ }^{1}$ Çukurova Üniversitesi, Ceyhan Mühendislik Fakültesi, Harita Mühendisliği Bölümü, Ceyhan/Adana \\ (asekertekin@cu.edu.tr) ORCID ID 0000-0002-4715-5160 \\ ${ }^{2}$ Zonguldak Bülent Ecevit Üniversitesi, Mühendislik Fakültesi, Geomatik Mühendisliği Bölümü, Zonguldak \\ (aycanmarangoz@hotmail.com) ORCID ID 0000-0003-4409-6000
}

\begin{abstract}
$\ddot{O} \mathbf{z}$
$\mathrm{Bu}$ çalışmanın amacı, Zonguldak metropolitan alanı için Landsat 8 uydusuna ait veriler yardımıyla Arazi Kullanımı Arazi Örtüsü (AKAÖ) ve Yer Yüzey Sıcaklığı (YYS) arasındaki ilişkinin araştırılmasıdır. Bu kapsamda 24 Mayıs 2017 tarihinde alınan Landsat 8 uydu görüntüsü kullanılmıştır. YYS çıkarımı için pratik bir yöntem olan mono-window algoritması ele alınmıştır ve AKAÖ haritalarının oluşturulması için piksel tabanlı maksimum benzerlik yönteminden yararlanılmıştır. YYS görüntüsünün doğruluk analizlerini gerçekleştirmek için uydu verisi ile eş zamanlık olarak arazi çalışması gerçekleştirilmiştir. Arazi çalışmasında, data loggerlar yardımıyla eş dağılımlı noktalarda sıcaklık ve nem ölçümleri gerçekleştirilmiştir. Elde edilen YYS değerleri ile yersel ölçümlerle elde edilen yakın hava sıcaklığı değerleri arasındaki korelasyon katsayısı (R) \%83 olarak belirlenmiştir. Ayrıca, üç yüz rastgele nokta seçilerek gerçekleştirilen AKAÖ haritasının doğruluk analizinde, ortalama doğruluk ve Kappa değeri sırasıyla $\% 90$ ve 0.86 olarak belirlenmiştir. YYS görüntüsü AKAÖ haritas1 arasındaki ilişkiyi incelemek için her bir AKAÖ sınıfından kesitler alınarak bu kesitlere karşılık YYS değerleri çıkarılmıştır. Genel olarak, yerleşim alanları ile açı yüzeyler yüksek YYS değerlerine sahipken, ormanlık ve bitki örtüsü ile kaplı alanlardaki YYS değerlerinin daha düşük olduğu gözlemlenmiştir. Yerleşim yerlerindeki YYS değerlerinin, bitki örtüsü kaplı alanlara nazaran ortalama $4{ }^{\circ} \mathrm{C}$ daha yüksek olduğu tespit edilmiştir.
\end{abstract}

Anahtar Kelimeler: Landsat-8, Bölgesel İklim Değişikliği, Yer Yüzey Sıcaklı̆̆l, Arazi Kullanımı Arazi Örtüsü, Mono-window Algoritmasl

\section{The Impact of Land Use Land Cover on Land Surface Temperature in Zonguldak Metropolitan Area}

\begin{abstract}
The goal of this study is to examine the impact of Land Use Land Cover (LULC) on Land Surface Temperature (LST) using Landsat 8 satellite data for Zonguldak metropolitan region. In this context, Landsat 8 satellite image acquired on May 24, 2017 was used. Mono-window algorithm, which is a practical method for LST extraction, was utilized and the pixel-based maximum likelihood method was performed for the generation of LULC maps. Field work was performed simultaneously with the satellite data to carry out the accuracy analysis of the LST image. In the field study, temperature and humidity parameters were measured with the help of dataloggers in uniformly distributed points. The correlation coefficient (R) between LST and the near-air temperature, obtained by ground measurements, was determined as $83 \%$.
\end{abstract}

* Sorumlu Yazar 
In addition, the overall accuracy and kappa values were determined as $90 \%$ and 0.86 , respectively, in the accuracy analysis of the LULC map by selecting three hundred random points. In order to reveal the impact of LULC on LST, cross-sections from each class of LULC were taken and YYS values were obtained for these cross-sections. In general, open areas and settlement areas have high LST values, while vegetation and forest areas have low LST values. It was determined that the LST values in the settlement area were $4{ }^{\circ} \mathrm{C}$ higher than the vegetated areas.

Keywords: Landsat-8, Regional Climate Change, Land Surface Temperature, Land Use Land Cover, Monowindow Algorithm

\section{GİRIŞ}

Son yıllarda etkisini hızlı bir şekilde göstermeye başlayan küresel isınma nedeniyle bilim insanları bu çerçevedeki çalışmalarına hız vermiștir. Dünyanın doğal döngüsü içinde çevreye verilen zararların büyük bir bölümü insanoğlu tarafindan gerçekleştirilmektedir. İnsanoğlunun verdiği zararların yanında, sanayileşme ve gelişen teknoloji ile birlikte bu süreçlerin çevreye olan etkilerinin göz ardı edilmesi çevremizdeki doğal döngünün düzgün bir şekilde çalışmamasına neden olmaktadır (Sekertekin, Kutoglu, \& Kaya, 2016).

Termal uzaktan algilama, uzaktan algilama teknolojisinin bir alt dalı olmakla beraber cisimlerin yaydığı radyasyonu belirleyerek sahip oldukları 1sı enerjisini konumsal olarak ortaya koymak için kullanılmaktadır (Merry 2004). İklim araştırmaları çerçevesinde, termal uzaktan algilama maliyet ve zaman bakımından geleneksel yöntemlerden daha avantajlidır. Aynı zamanda geniş ölçekte uygulanabilirliği açısında da cazip bir yöntemdir.

Yer Yüzey Sıcaklığı (YYS), yer yüzeyi ve atmosfer arasındaki etkileşimi açıklayan ve bu ikili arasındaki enerjiyi kontrol eden bir parametredir. Ayrıca, çevresel kaynakların sürekli değişimini yönlendiren bir etkendir (Zhihao Qin \& Karnieli, 1999). Uydu verileri ile YYS tahmini için birçok algoritma geliştirilmiştir ve bu detaylar sonraki bölümlerde detaylı olarak sunulmuştur. Meteoroloji istasyonları da 1şınım ölçümleri yaparak YYS değerlerini elde edebilir ancak bu ölçümler nokta tabanlı olduğu için topoğrafyayı temsil edememektedir. Ayrıca, bu tür istasyonların kurulması ve bakımları maliyetli işlemlerdir.

Termal uzaktan algilama verileri ile YYS görüntülerinin elde edilmesi, bölgesel iklim değișikliğinin gözlemlenmesi açısından önemli olmasının yanı sıra iklim modelleme ve Coğrafi Bilgi Sistemi (CBS) çalışmaları için de altlık veri olarak kullanılabilmektedir. ABD ulusal havacılık uzay dairesi (NASA) tarafindan uzaya gönderilen Landsat 8 uydusu, iki adet termal banda sahiptir ve iklim değişikliği ile birçok farklı çevresel uygulamada kullanılmak üzere tasarlanmıştır. Önceki Landsat programlarının bilim dünyasına kattığı çalışmalar göz önüne alındığında Landsat 8 uydu görüntüleri de birçok bilimsel çalışmaya katkıda bulunacaktır. Yapılan literatür taramasında Arazi Kullanımı Arazi Örtüsü (AKAÖ) ve YYS arasındaki ilişkiyi inceleyen bir çok çalışma gerçekleştirilmiştir (Amiri, Weng, Alimohammadi, \& Alavipanah, 2009; Balcik, 2014; Balçık \& Ergene, 2017; Cicek, Yilmaz, Turkoglu, \& Caliskan, 2013; Duman Yüksel \& Y1lmaz, 2008; Guo, Wang, Cheng, \& Shu, 2012; Jiang, Fu, Weng, Baghdadi, \& Thenkabail, 2001; Kaya, Basar, Karaca, \& Seker, 2012; Li et al., 2011; Onishi, Cao, Ito, Shi, \& Imura, 2010; Qian, Cui, \& Jie, 2006; Şekertekin, Kutoğlu, Kaya, \& Marangoz, 2015; Şensoy et al., 2017; Shen, Huang, Zhang, Wu, \& Zeng, 2016; Xiao \& Weng, 2007). Bu çalışmaların sonuçları genellikle benzerlik göstermekle beraber, çalışmalarda; yerleşim ve açık yüzeylerin YYS değerleri, öteki arazi sinıflarına göre daha yüksekken, ormanlık ve bitki örtüsü olan alanların daha düşük YYS değerlerine sahip olduğu belirlenmiştir.

Bu çalışmanın amacı; Landsat 8 uydu verilerini kullanarak Zonguldak bölgesi için AKAÖ'den kaynaklanan YYS değişimlerini analiz etmek ve sonuçlarını sunmaktır. Bu kapsamda ele alınan Landsat 8 uydusuna ait görüntüler Amerikan Jeoloji Birliği (USGS) tarafindan ücretsiz olarak temin edilmiştir. Çalışmada, Qin vd. (2001) tarafindan YYS elde etmek için geliștirilen mono-window yöntemi kullanılmıştır. Ayrıca, AKAÖ haritalarının elde edilmesi için piksel-tabanlı maksimum benzerlik sınıflandırma yöntemi ele alınmıştır.

\section{CALISMA ALANI VE MATERYAL}

Çalışma alanı olarak, içerisinde Zonguldak Bülent Ecevit Üniversitesi merkez kampüslerinin de yer aldığı Karadeniz 
kıyısında bulunan $3.306 \mathrm{~km}^{2}$ yüzölçümüne, 597,524 toplam nüfusa sahip ve geçiminin büyük bir kısmını taş kömürü madenlerinden sağlayan, merkezi yaklaşık $10 \mathrm{~m}$ rakıma sahip olan Zonguldak ili ve çevresi seçilmiştir (Şekil 1).

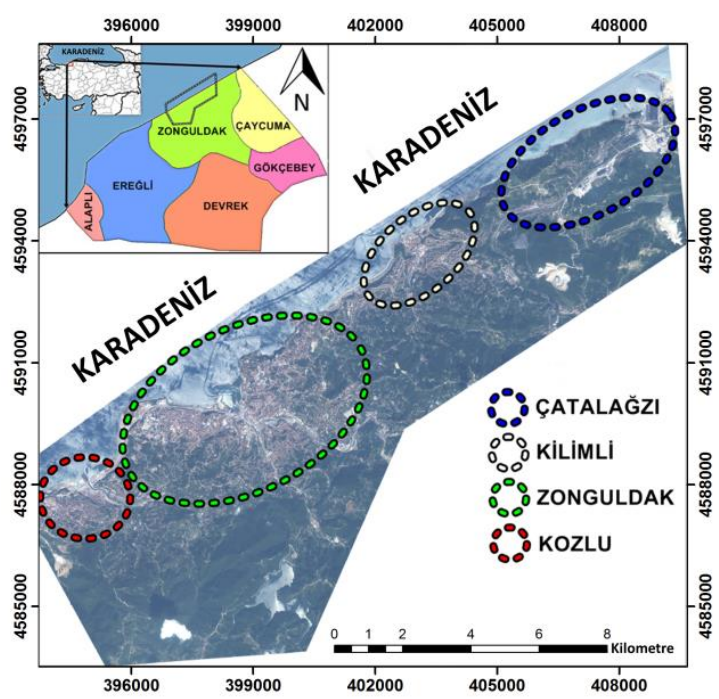

Şekil 1. Çalışma Alanının RGB formatında sunulmuş Worldview-2 Uydu Görüntüsü.

Uydu verisi olarak 24 Mayıs 2017 tarihinde çekimi gerçekleştirilen Landsat 8 görüntüsü kullanılmıştır. Landsat 8 Operational Land Imager (OLI) ve Termal Infrared Sensor (TIRS) olmak üzere iki temel sensöre sahiptir (Tablo 2). OLI sensöründen elde edilen veriler daha önceki Landsat sensörlerine ait verilerle kıyaslandığında derin mavi band kıyı/aerosol çalışmaları için, kısa dalga kızılötesi bandı sirrus bulutlarının tespiti için kullanılmaktadır. Ayrıca, sensör kalite değerlendirme bandı içermektedir. TIRS sensörü ise termal bant verilerini içermektedir. $\mathrm{Bu}$ veriler, kurak arazide su kullanımı ve kentsel alanlardaki is1 adacıkları hakkında önemli bilgiler sağlamaktadır (Liu \& Zhang, 2011; Moyano et al., 2018; Sekertekin, Kutoglu, Marangoz, \& Kaya, 2016).

Çalışmada uydu verisi ile eş zamanlı olarak arazi çalışması gerçekleştirilmiştir. Arazi çalışmasında DS100 marka sıcaklık ve nem ölçerler kullanılarak YYS görüntülerinden elde edilen değerler ile bu ölçümler karşılaştırılmıştır.

\section{YÖNTEM}

$\mathrm{Bu}$ bölümde, YYS çıkarımında kullanılan algoritma ile AKAÖ haritalarının elde edilmesinde kullanılan yöntemler hakkında bilgiler sunulmuştur. Ayrıca, gerçekleştirilen doğruluk analizleri hakkında bilgiler verilmiştir.

\subsection{YYS Çıkarımı}

Termal verilerle YYS elde etme yöntemleri, farklı veri kaynakları ve parametreler göz önüne alınarak geliştirilmiştir. "Single channel" yöntemi (Duan et al., 2018; Jiménez-Muñoz \& Sobrino, 2003), "mono-window" yöntemi (Z. Qin, Karnieli, \& Berliner, 2001), sıcaklık/yayınırlık ayırma yöntemi (Gillespie et al., 1998) ve "split-window" yöntemi (Sobrino, Li, Stoll, \& Becker, 1996) en çok kullanılan YYS elde etme algoritmalarıdır. "Monowindow" algoritmas1 (MWA), pratik bir YYS elde etme yöntemi olduğu ve yüksek doğruluklu sonuçlar sunduğu için bu çalışmada tercih edilmiştir. Ek olarak, orijinalinde Landsat $6 \mathrm{TM}$ uydu verisi kullanılarak geliştirilen MWA bu çalışma ile Landsat 8 verisine uyarlanmıştır. Bu kapsamda Landsat 8 uydusuna ait 4. Band (Kırmızı), 5. Band (Yakın Kızılötesi: NIR) ile 10. (Termal) bandları YYS elde etmek için kullanılmıştır. Ortalama atmosferik sıcaklık, atmosferik geçirgenlik ve yayınırlık MWA algoritması için gerekli üç ana parametredir. Avdan ve Jovanovska tarafindan (2016) gerçekleştirilen çalışmada; YYS görüntüsünün otomatik elde edilmesine yönelik ERDAS Imagine yazılımı ile bir model oluşturulmuştur. $\mathrm{Bu}$ çalışma kapsamında da ERDAS Imagine yazilımında bir model oluşturularak MWA yöntemi ile otomatik olarak YYS görüntüsü elde edilmiştir. MWA temel olarak aşağıda belirtilen 7 alt başlık altında incelenebilir.

\subsubsection{Radyans Dönüşümü}

(1) nolu eşitlik kullanılarak parlaklık değerleri radyans değerlerine dönüştürülür ve bu dönüşüm genellikle termal bandlara uygulanmaktadır. $\mathrm{Bu}$ dönüşüm işlemi ile, görüntüde parlaklık ve kontrast düzeltmesi yapılmış olur (Milder 2008).

$$
\mathrm{L}_{\lambda}=\mathrm{M}_{\mathrm{L}} \cdot \mathrm{Q}_{\mathrm{cal}}+\mathrm{A}_{\mathrm{L}}
$$

$\mathrm{Bu}$ denklemde, $\mathrm{L}_{\lambda}$ radyans değerini, $\mathrm{M}_{\mathrm{L}}$ banda özel çarpımsal yeniden ölçekleme değerini, $A_{L}$ banda özel toplamsal yeniden örnekleme değerini, $\mathrm{Q}_{\text {cal }}$ dijital piksel değerlerini ifade 
etmektedir. $M_{L}$ ve $A_{L}$ değerleri, görüntü metaveri dosyasından alınır.

\subsubsection{Parlaklık değerlerinin yansıtım değerlerine dönüștürülmesi}

Termal banda uygulanan radyans dönüşümü sonrasinda 4 ve 5 nolu bandlar için parlaklık değerlerinin yansitım değerlerine dönüştürülmesi işlemi (2) nolu denklem ile gerçekleştirilir. 4 ve 5 nolu bandlar için dönüşüm yapıldıktan sonra öncelikle Normalize Edilmiş Fark Bitki Örtüsü İndeksi (NDVI) hesaplanır ve NDVI ile daha sonraki adımlardan biri olan yayınırlık hesabı gerçekleştirilir. Algılayıcı yansıtım değerleri hesabı, solar yükseklik açısı ve dünya-güneş mesafesi gibi sensör ve gezegensel etkileri düzeltmek için yapılır (Milder 2008).

$$
\rho_{\lambda}=\frac{\mathrm{M}_{\mathrm{p}} \cdot \mathrm{Q}_{\mathrm{cal}}+\mathrm{A}_{\mathrm{p}}}{\sin \theta_{\mathrm{SE}}}
$$

Burada, $\rho_{\lambda}$ yansıtım değerlerini, $M_{p}$ banda özel çarpımsal yeniden ölçekleme değerini, $A_{p}$ banda özel toplamsal yeniden örnekleme değerini, $\theta_{\mathrm{SE}}$ güneş yükseklik açısını ifade etmektedir. $\mathrm{Bu}$ değerler ilgili görüntünün metadata dosyasından elde edilebilir.

\subsubsection{Radyans değerlerinin parlaklık sıcaklığı değerlerine dönüştürülmesi}

Landsat 8 termal bandları için (3) eşitliğindeki denklem yardımıyla radyans değerlerinin parlaklık sıcaklığı değerlerine dönüştürülmesi işlemi gerçekleştirilir.

$$
\mathrm{T}=\frac{\mathrm{K}_{2}}{\ln \left(\frac{\mathrm{K}_{1}}{\mathrm{~L}_{\lambda}}+1\right)}
$$

Burada; $\mathrm{T}$ Kelvin cinsinden sensördeki parlaklık sicaklığı değerini, $\mathrm{K}_{1}$ ve $\mathrm{K}_{2}$ sırasiyla birinci ve ikinci kalibrasyon sabitlerini, $\mathrm{L}_{\lambda}$ spektral radyans değerini temsil etmektedir. Landsat 8 uydusu için $\mathrm{K}_{1}$ ve $\mathrm{K}_{2}$ kalibrasyon sabitleri sirasiyla 774.89 ve 1321.079 'dur.

\subsubsection{Yer yüzey yayınırlığı $\left(\varepsilon_{\mathrm{i}}\right)$ hesabı}

Yayınırlık; cisme gelen toplam 1şın enerjisinin, emilen 1şın enerjisine oranı olarak tanımlanmakla beraber kara cisim teorisiyle açıklanabilmektedir. Cisim veya yüzey ne kadar mat ve siyah olursa, yayınırlığı bir (1) değerine o kadar yakın olur. Aksi halde, cismin yansıtıcılığg arttıkça sahip olduğu yayınırlık değeri düşer. Yayınırlık hesabı NDVI değerleri yardımıyla hesaplanabilmektedir. NDVI hesabı için yansıtım değerleri hesaplanmış görüntülerden 5 . bant olan NIR ve 4 . bant olan kırmızı (R) bant arasında (4) eşitliğinde görüldüğü gibi matematiksel bir işlem yapmak gerekir.

$$
\mathrm{NDVI}=\frac{\rho_{\mathrm{NIR}}-\rho_{\mathrm{R}}}{\rho_{\mathrm{NIR}}+\rho_{\mathrm{R}}}
$$

Van de Griend \& Owe (1993) NDVI değerleri 0.157 ile 0.727 arasında değişen yerlerin yüzey yayınırlık tahmini için ileri sürmüştür. NDVI tabanlı yayınırlık görüntüsü elde edebilmek için Tablo 4'deki koşul değerlerinden faydalanılabilir. Tablo 1'de NDVI değerleri 0.157 ile 0.727 dışında kalan değerlerden yayınırlık hesabı yapabilmek için Sobrino vd. ( 2008) tarafindan sunulan ifadeler kullanılmıştır.

Tablo 1. NDVI Verileri ile Yayınırlık Hesabı.

\begin{tabular}{|l|l|}
\hline $\mathrm{NDVI} \leq 0$ & $0.979-\rho_{\mathrm{R}}{ }^{*} 0.035$ \\
\hline $0<\mathrm{NDVI} \leq 0.72$ & $1.00094+\log (\mathrm{NDVI} * 0.04$ \\
7 & 7 \\
\hline $\mathrm{NDVI}<1$ & 0.99 \\
\hline
\end{tabular}

\subsubsection{Atmosferik geçirgenlik hesabı $\left(\tau_{\mathbf{i}}\right)$}

Atmosferik geçirgenlik, su buharı içeriği kullanılarak tahmin edilebilir (Liu \& Zhang, 2011). Su buharı içeriği, meteorolojik istasyonlardan temin edilebilir veya yakın yüzey sıcaklığı ve bağıl nem değerleri ile hesaplanabilmektedir. Su buharı içeriğine bağlı atmosferik geçirgenlik tahmininde kullanılan denklemler Tablo 2'de gösterilmektedir (Liu \& Zhang, 2011).

Tablo 2. Su Buharı ile Atmosferik Geçirgenlik Tahmini.

\begin{tabular}{|c|r|r|}
\hline Profiller & $\begin{array}{c}\text { Su Buharı } \\
\left(\mathbf{w}_{\mathbf{i}}\right)\left(\mathbf{g} / \mathbf{c m}^{\mathbf{2}}\right)\end{array}$ & $\begin{array}{c}\text { Geçirgenlik tahmini } \\
\text { denklemi }\left(\boldsymbol{\tau}_{\mathbf{i}}\right)\end{array}$ \\
\hline $\begin{array}{c}\text { Yüksek } \\
\text { Hava } \\
\text { Sicaklığ }\end{array}$ & $0.4-1.6$ & $0.974290-0.0801 \times$ wi \\
\cline { 2 - 3 } & $1.6-3.0$ & $1.031412-0.1154 \times$ wi \\
\hline $\begin{array}{c}\text { Düşük } \\
\text { Hava } \\
\text { Sicaklığ }\end{array}$ & $0.4-1.6$ & $0.982007-0.0961 \times$ wi \\
\cline { 2 - 3 } & $1.6-3.0$ & $1.053710-0.1414 \times$ wi \\
\hline
\end{tabular}




\subsubsection{Ortalama atmosferik sicaklık $\left(T_{a}\right)$ hesabi}

Algoritmanın altıncı adımı, ortalama atmosferik sicaklık $\left(\mathrm{T}_{\mathrm{a}}\right)$ hesabıdır. Ortalama atmosferik sıcaklık hesabı, yakın yüzey sıcaklığına $\left(T_{0}\right)$ bağlı olarak (5) nolu denklem esas alınarak hesaplanabilmektedir (Z. Qin et al., 2001).

$\mathrm{T}_{\mathrm{a}}=16.0110+0.92621 \times \mathrm{T}_{\mathrm{o}}$

\subsubsection{MWA ile YYS hesabı}

Yukarıda belirtilen adımlar tamamlandıktan sonra son olarak (6) nolu algoritma denklemi kullanılarak YYS görüntüsü elde edilir. (6) nolu eşitlikten anlaşılacağı üzere yayınırlık, atmosferik geçirgenlik ve ortalama atmosferik sıcaklık verileri kullanılarak YYS görüntüsü oluşturulmaktadir.

$$
\mathrm{T}_{\mathrm{s}}=\left\{\mathrm{a}(1-\mathrm{C}-\mathrm{D})+[\mathrm{b}(1-\mathrm{C}-\mathrm{D})+\mathrm{C}+\mathrm{D}] \mathrm{T}_{\mathrm{i}}-\mathrm{DT} \mathrm{T}_{\mathrm{a}}\right\} \div \mathrm{C}
$$

(6) eşitliğinde; $a=-67.355351$ ve $b=0.458606$ algoritma sabitlerini ifade etmektedir. $\mathrm{C}=\varepsilon_{\mathrm{i}} \times$ $\tau_{\mathrm{i}}, \mathrm{D}=\left(1-\tau_{\mathrm{i}}\right)\left[1+\left(1-\varepsilon_{\mathrm{i}}\right) \times \tau_{\mathrm{i}}\right]$ şeklindedir. $\mathrm{T}_{\mathrm{s}}$, yer yüzey sıcaklığını (Kelvin), $\mathrm{T}_{\mathrm{i}}$, parlaklık sıcaklığını (Kelvin), $\varepsilon_{i}$ yer yüzey yayınırlı̆̆ını, $\tau_{\mathrm{i}}$ atmosferik geçirgenliği ve $\mathrm{T}_{\mathrm{a}}$ efektif ortalama atmosferik sicaklığı temsil etmektedir. Çalışmada, MWA ile Kelvin cinsinden elde edilen YYS görüntüsü Santigrat dereceye $\left({ }^{\circ} \mathrm{C}\right)$ dönüştürülmüştür.

\subsection{AKAÖ Haritalarının Çıkarımı}

Piksel-tabanlı maksimum benzerlik sınıflandırma yöntemi, görüntü sınıflandırmak için en sık kullanılan kontrollü sınıflandırma yöntemidir. Bu yöntem ile her bir sinıf için eş olasılık eğrileri tanımlanarak sınıflandırmaya tabi olacak piksellerin, üyelik olasılığı en yüksek olan sinıfa dahil edilmesi ilkesine dayanır ve bu olasılığın hesabı (7) nolu eşitlikte gösterildiği gibi hesaplanır. Maksimum benzerlik yönteminin performansı, her sınıf için hesaplanan ortalama vektör ve kovaryans matrisin doğru tahmin edilmesine bağlidır (Benediktsson, Swain, \& Ersoy, 1990).
Çalışmada AKAÖ görüntüleri bu yönteme göre sinıflandırılmıştır.

$\mathrm{g}_{\mathrm{i}}(\mathrm{x})=\ln \mathrm{p}\left(\mathrm{w}_{\mathrm{i}}\right)-\frac{1}{2} \ln |\Sigma \mathrm{i}|-\frac{1}{2}\left(\mathrm{x}-\mathrm{m}_{\mathrm{i}}\right)^{\mathrm{T}} \Sigma \mathrm{i}^{-1}(\mathrm{x}-$

$\left.\mathrm{m}_{\mathrm{i}}\right) \quad(7)$

Burada i sinıfi, $\mathrm{x} n$ boyutlu veriyi, $\mathrm{p}\left(\mathrm{w}_{\mathrm{i}}\right)$ görüntüde oluşan $\mathrm{w}_{\mathrm{i}}$ sınıfının olasılığını, $\left|\sum \mathrm{i}\right| \mathrm{w}_{\mathrm{i}}$ sinıfindaki verinin kovaryans matrisinin determinantını, $\Sigma \mathrm{i}^{-1}$ ters matrisini ve $\mathrm{m}_{\mathrm{i}}$ ortalama vektörü ifade etmektedir.

\subsection{Doğruluk Analizleri}

Elde edilen YYS görüntülerinin doğruluk analizi için uydu verisi ile eş zamanlı olarak arazi çalışması gerçekleştirilmiştir. Arazi ölçümlerine uydu geçişi sırasında başlanarak her noktada en az 3 dakika ölçüm yapmak üzere veriler kaydedilmiştir ve her noktada ortalama değerler dikkate alınmıştır. Tüm arazi çalışması yaklaşık 4 saat sürmüştür Arazi çalışmasında Şekil 2'de gösterilen noktalarda sıcaklık ve nem ölçümleri kaydedilmiştir. Sicaklık ve nem ölçümleri alınan noktalarda arazi yapısının en azında 30x30m (1 piksel boyutu) boyutunda yanı yapıda olmasina dikkat edilmiştir. Örneğin, kentsel alanda yapılan ölçümlerde 30x30m lik bir alanda bitki örtüsünün olmamasina tamamen kentsel yapıların olmasına dikkat edilmiştir.

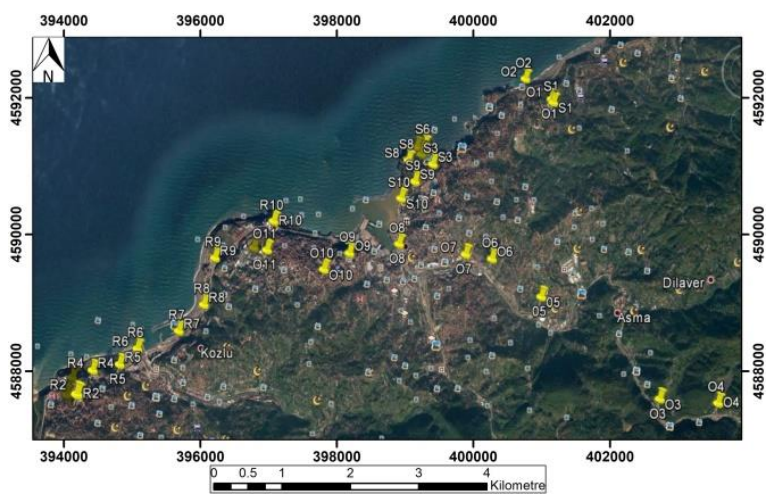

Şekil 2. Arazi Çalışması için Belirlenen ve Ölçüm Yapılan Homojen Dağılımlı Noktalar.

Yapılan sıcaklık ölçümlerinin hava sıcaklığını temsil etmesi ve nokta bazlı olması uydu verisinden elde edilen piksel tabanlı YYS değerini tam olarak karşılamasa bile literatürde bu karşılaştırmalara yer verilmiştir.

Ayrıca, AKAÖ haritalarının doğruluk analizi için rastgele seçilen 300 nokta kullanılmıştır. 
$\mathrm{Bu}$ şekilde, ortalama doğruluk ve Kappa istatistiki değeri elde edilmiştir.

\section{BULGULAR}

$\mathrm{Bu}$ bölümde, 3 . bölümünde belirtilen algoritmalara göre oluşturulan YYS ve AKAÖ görüntüleri sunulmuştur. Şekil 3'te yoğunluk dilimleme (density slicing) yöntemi ile sinıflandırılmış YYS görüntüsü gösterilmektedir. Görüntü Santigrat derece $\left({ }^{\circ} \mathrm{C}\right)$ cinsinden sicaklığ renkten kırmızı renge doğru gidildikçe YYS değerlerinin arttığ1 gözlemlenmektedir. Görüntünün alındığı zaman diliminde çalışma alanı üzerinde bulut örtüsü de bulunduğu için Şekil 3'te mavi renkli alanlar bulut yapılarını temsil etmektedirler. Bulutlar yer yüzeyinden çok yukarda oldukları için YYS değerlerinin çok düşük olduğu görülmektedir. Yeşil alanlar su yapısı, orman ve bitki örtüsü olan alanları temsil ederken; sarı alanlar genellikle üzerinde bitki örtüsü ve yerleşim olmayan çıplak arazileri ifade etmektedir. Kırmızı alanlar ise yerleşim, endüstriyel alanlar ve kumsal yapılarını ifade etmektedirler. Ayrıca çalışma bölgesinde yer alan açık kömür stok alanları da kırmızı renkte görünmektedir.

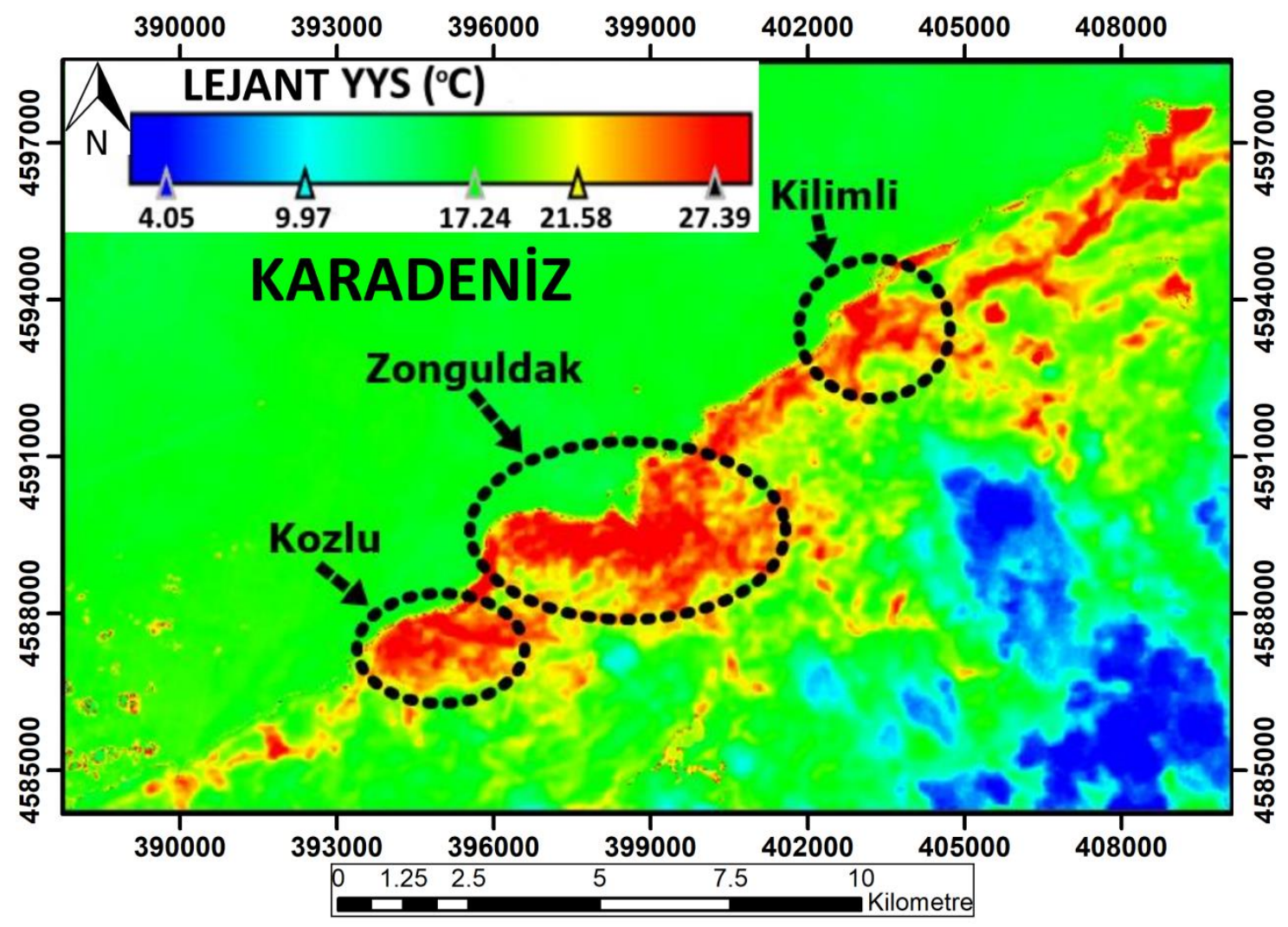

Şekil 3. 24 Mayıs 2017 Tarihli Landsat 8 Görüntüsünden MWA kullanılarak üretilen YYS Görüntüsü.

YYS görüntüsünün doğruluk değerlendirmesi için arazi çalıșmasından elde edilen yakın hava sıcaklığı değerleri aynı noktalardaki YYS değerleri ile regresyon analizine tabi tutulmuştur (Tablo 3, Şekil 4). YYS değerleri yüzeyin sıcaklığını temsil etmesine karşın, doğruluk değerlendirmesinde yakın hava sıcaklığının kullanılması göreceli bir karş1laştırma yöntemi olarak literatürde yer almaktadır.
Şekil 4'te YYS değerleri ile yakın yüzey sıcaklığ1 arasındaki regresyon analizinde korelasyon katsayısının (R) \%83 gibi yüksek bir değerde olduğu ve Karesel Ortalama Hata $(\mathrm{KOH})$ 'nın $1.61 \mathrm{~K}$ olduğu görülmektedir. Ayrica, Landsat verisinin kısa bir zaman diliminde alınmasına karşın arazi çalışmasının daha uzun bir süre alması ve çalışma alanında yeterinde eş dağılımlı meteoroloji istasyonunun olmaması çalışmanın bir kısıtlaması olarak görülmektedir. 
Tablo 3. YYS ve İlgili Piksellere Karşılık Gelen Arazi Ölçümlerinden Elde Edilen Yakın Hava Sicaklığı Değerleri.

\begin{tabular}{|l|l|l|l|}
\hline $\begin{array}{c}\text { YYS } \\
\text { Değeri } \\
\left({ }^{\circ} \mathrm{C}\right)\end{array}$ & $\begin{array}{c}\text { Yakın } \\
\text { Hava } \\
\text { S1caklığı } \\
\left({ }^{\circ} \mathrm{C}\right)\end{array}$ & $\begin{array}{c}\text { YYS } \\
\text { Değeri } \\
\left({ }^{\circ} \mathrm{C}\right)\end{array}$ & $\begin{array}{c}\text { Yakın } \\
\text { Hava } \\
\text { S1caklığ } \\
\left({ }^{\circ} \mathrm{C}\right)\end{array}$ \\
\hline 22.10 & 20.77 & 26.80 & 25.17 \\
\hline 22.40 & 21.38 & 26.81 & 26.54 \\
\hline 23.85 & 21.55 & 26.80 & 28.41 \\
\hline 24.50 & 23.25 & 27.21 & 27.09 \\
\hline 24.50 & 23.05 & 27.30 & 25.89 \\
\hline 24.65 & 25.33 & 27.30 & 25.62 \\
\hline 25.10 & 23.70 & 27.20 & 25.19 \\
\hline 25.30 & 23.18 & 27.65 & 29.39 \\
\hline 25.20 & 23.17 & 28.10 & 27.02 \\
\hline 25.09 & 21.78 & 28.09 & 25.68 \\
\hline 25.73 & 26.97 & 28.25 & 30.16 \\
\hline 26.23 & 27.21 & 28.28 & 27.16 \\
\hline 26.30 & 25.33 & 28.52 & 27.46 \\
\hline 26.51 & 26.41 & 28.97 & 26.89 \\
\hline 26.51 & 24.26 & 29.16 & 28.89 \\
\hline 26.70 & 24.75 & & \\
\hline
\end{tabular}

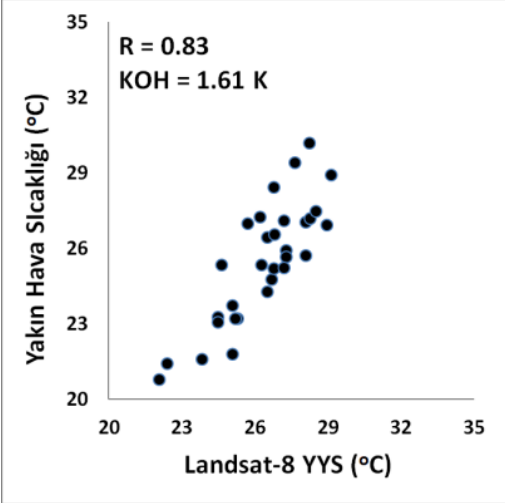

Şekil 4. YYS ve Yakın Hava Sicaklığı Arasındaki İlişkinin Grafiksel Olarak Gösterimi.

Kontrollü siniflandırma yöntemiyle sinıflandırılan Landsat uydu görüntüsünden elde edilen AKAÖ görüntüsü Şekil 5'te sunulmuştur. Sınıflandırılmış görüntü; su yapısı, açık alan, yeşil alan, yerleşim, orman, deniz ve bulut olmak üzere yedi temel siniftan oluşmaktadır. Denizden ayrı olarak su yapısı sınıfı, baraj gölü vb. tatlı su yapılarını ifade etmektedir. Tablo 3 'te gerçekleştirilen doğruluk analizinin sonuçları sunulmuştur. Sinıflandırmanın ortalama doğruluğu \%90.33, ortalama Kappa değeri ise 0.86 olarak belirlenmiştir.

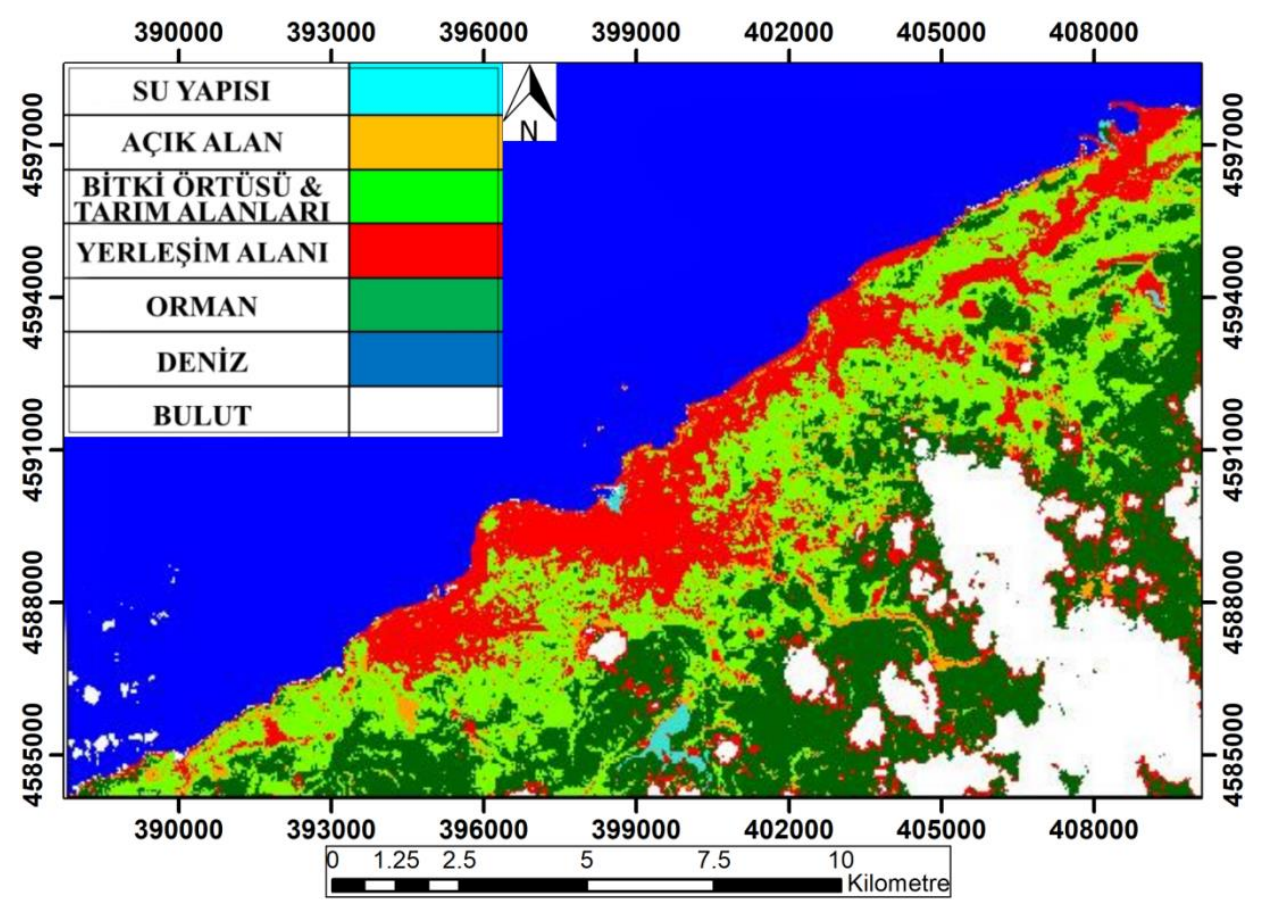

Şekil 5. 24 Mayıs 2017 Tarihli Landsat 8 Uydu Görüntüsünden Elde Edilen AKAÖ Haritası. 
Tablo 3. AKAÖ Haritası için Doğruluk Analizi Tablosu.

\begin{tabular}{|l|c|c|c|c|c|}
\hline Sınıf İsmi & $\begin{array}{c}\text { Referans } \\
\text { Toplamları }\end{array}$ & $\begin{array}{c}\text { Sinıflandırma } \\
\text { Toplamları }\end{array}$ & $\begin{array}{c}\text { Doğru } \\
\text { Nokta }\end{array}$ & $\begin{array}{c}\text { Üretici } \\
\text { Doğruluğu }\end{array}$ & $\begin{array}{c}\text { Kullanıcı } \\
\text { Doğruluğu }\end{array}$ \\
\hline Su Yapısı & 2 & 1 & 1 & $50.00 \%$ & $100.00 \%$ \\
\hline Açı Alan & 4 & 3 & 3 & $75.00 \%$ & $100.00 \%$ \\
\hline $\begin{array}{l}\text { Bitki Örtüsü ve Tarım } \\
\text { Alanları }\end{array}$ & 37 & 30 & 25 & $67.57 \%$ & $83.33 \%$ \\
\hline Yerleşim Alanı & 18 & 30 & 18 & $100.00 \%$ & $60.00 \%$ \\
\hline Orman & 53 & 57 & 46 & $86.79 \%$ & $80.70 \%$ \\
\hline Deniz & 153 & 154 & 153 & $100.00 \%$ & $99.35 \%$ \\
\hline Bulut & 33 & 25 & 25 & $75.76 \%$ & $100.00 \%$ \\
\hline Toplam & 300 & 300 & 271 & & \\
\hline \multicolumn{5}{|l|}{} \\
\hline
\end{tabular}

YYS ve AKAÖ sınıfları arasındaki ilişkiyi daha anlaşılır bir biçimde ortaya koymak için Şekil 6'da gösterilen grafik çizilmiştir. Her bir arazi sınıfı için kesitler alınarak hazırlanan bu grafikten anlaşılacağ 1 üzere yerleşim ve açık alanların en yüksek YYS değerlerine sahip olduğu ve orman sınıfinın en düşük YYS değerlerine sahip olduğu gözlemlenmektedir.

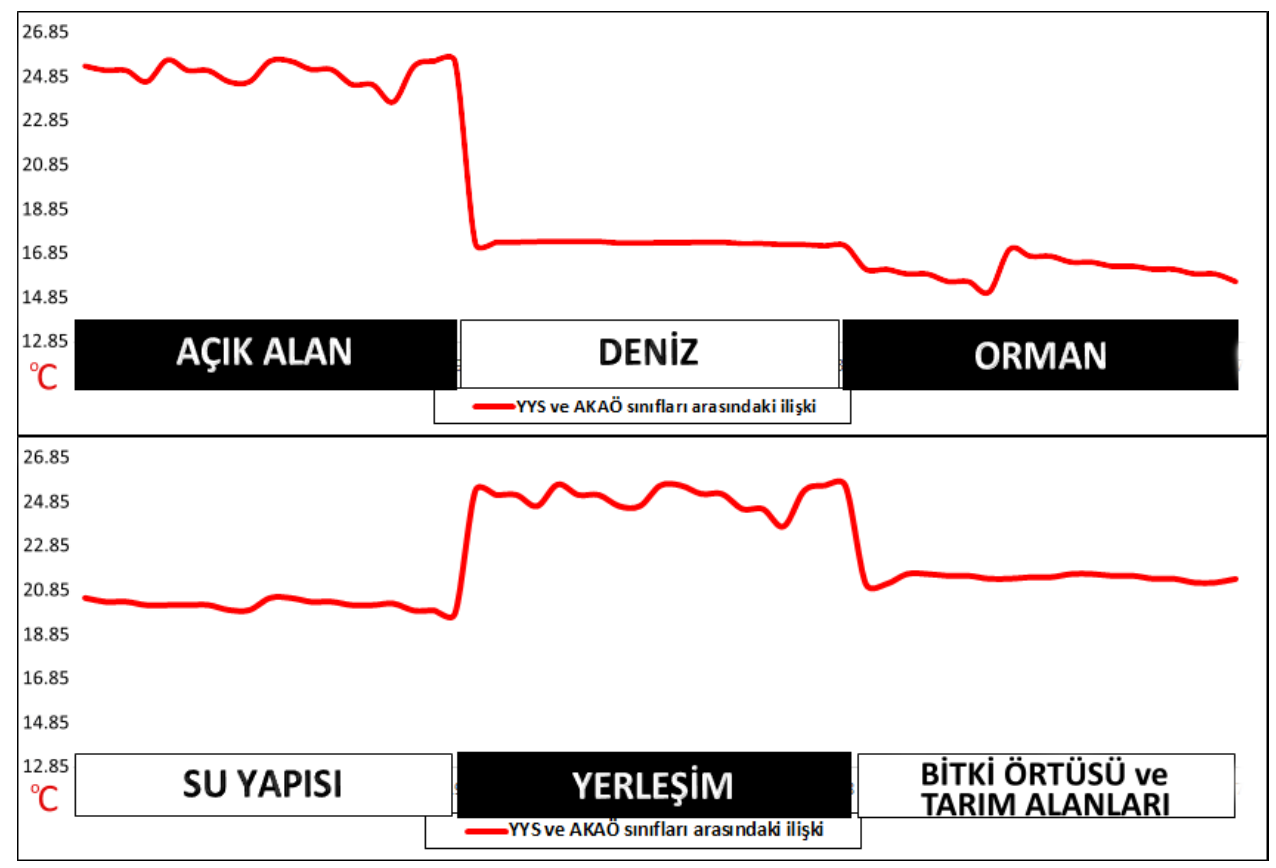

Şekil 6. 24 Mayıs 2017 Tarihli Landsat 8 Uydu Verilerinden Elde Edilen YYS ve AKAÖ Sınıfları Arasındaki İlişki Grafiği.

\section{SONUÇLAR}

Çalışma kapsamında 24.05.2017 tarihinde alınan Landsat 8 uydusuna ait görüntü kullanılarak bölgesel iklim değişikliğine etki eden önemli parametrelerden biri olan YYS görüntüsü elde edilmiştir. YYS görüntülerinin elde edilmesinde çok sık kullanılan "mono- window" algoritmasından faydalanılmıştır. Ayrıca YYS görüntüsünün doğruluk analizini gerçekleştirmek için uydu geçişi ile eş zamanlı olarak arazi çalışması gerçekleştirilerek çalışma alanında homojen dağılımlı noktalarda sıcaklık ve nem ölçümleri gerçekleştirilmiştir. 
Oluşturulan YYS görüntüleri, Landsat verilerinin kontrollü sınıflandırma yöntemine tabi tutularak elde edilen AKAÖ görüntüleri ile ilişkilendirilmiştir.

YYS görüntüsünde genel olarak, açık yüzeyler ile yerleşim alanlarının, ormanlık ve bitki örtüsü olan alanlara nazaran daha yüksek YYS değerlerine sahip olduğu görülmüştür. Yerleşim yerlerindeki YYS değerlerinin, bitki örtüsü kaplı alanlara nazaran ortalama $4{ }^{\circ} \mathrm{C}$ daha yüksek olduğu tespit edilmiştir. Şekil 6'da farklı arazi sınıflarının sahip olduğu YYS değerleri açık bir şekilde sunulmuştur. Şekil 6 'dan anlaşılacağı üzere, ormanlık ve yeşil alanların bölgesel iklim değişikliklerini önlemede önemli bir rol aldıkları sonucuna varılmaktadır.

Orman ve bitki örtüsü olan alanların tahribat1, sıcaklık rejimlerinin değişiminde kısa vadeli düşünüldüğünde çok fazla etkili olmayabilir ancak uzun vadeli olarak bölgesel iklim değișikliğine neden olma olasıllı̆̆ oldukça fazladır. Orman alanları ile Bitki Örtüsü ve Tarım Alanları ele alındığında orman alanlarının daha düşük YYS değerlerine sahip olduğu gözlemlenmektedir. Bunun nedeni; Bitki Örtüsü ve Tarım Alanları içerisinde kısmen yerleşimin olması, insan faaliyetlerinden dolayı tarım alanlarında sürekli bir vejetasyon düzenlenmesi ile yer yer açıklık alanlara rastlanılması ve vejetasyon kapalılığının orman alanı kadar yüzeyi \%70 ve yukarısında örtme yüzeyi olmadığından dolayıdır.

Landsat 8 uydu verilerine ek olarak Terra uydusu üzerinde yer alan ASTER sensörü tarafından kaydedilen görüntüler de YYS elde etmek için tercih edilebilir. ASTER sensörü 5 adet termal banda sahip olması nedeniyle bu sensörden elde edilen YYS sonuçlarının irdelenmesi de önemli katkılar sağlayacaktır. Ek olarak, günümüz teknolojisinde kullanım alanları hızla yayılan insansız hava araçlarına takılabilecek termal algilayıcılar yardımıyla da bir bölgenin YYS değerleri detaylı bir şekilde analiz edilebilir.

Çalışmada uydu verileri ile yapılan analizler sonucunda elde edilen bulgular, uzaktan algılama teknolojisinin çevresel gözlem ve değerlendirme çalışmalarında etkili bir yöntem olduğunu açıkça göstermektedir. Sözel ve sayısal verilere ek olarak görsel anlamda da sonuçlar veren bu teknoloji, çevreye etki eden parametrelerin belirlenmesi ve zamansal olarak gözlemlenmesi gibi özellikleri ile de diğer bilim dallarına nazaran ön plana çıkmaktadır. Son olarak, uzaktan algilama teknolojisi ile elde edilen tüm ürünler dijital formatta olduğu için oluşturulacak olası CBS programları için de altlık olarak kullanılabilmektedirler.

\section{TEŞEKKÜR}

Şekil 1'de sunulan Worldview-2 uydusuna ait görüntü Zonguldak Bülent Ecevit Üniversitesi tarafindan 2015-47912266-02 nolu Bilimsel Araştırma Projesi ile temin edilmiştir.

\section{KAYNAKÇA}

Amiri, R., Weng, Q., Alimohammadi, A., \& Alavipanah, S. K. (2009). Spatial-temporal dynamics of land surface temperature in relation to fractional vegetation cover and land use/cover in the Tabriz urban area, Iran. Remote Sensing of Environment, 113(12), 2606-2617.

https://doi.org/10.1016/j.rse.2009.07.021

Avdan, U., \& Jovanovska, G. (2016). Algorithm for Automated Mapping of Land Surface Temperature Using LANDSAT 8 Satellite Data. Journal of Sensors, 2016, 1-8. https://doi.org/10.1155/2016/1480307

Balcik, F. (2014). Determining the impact of urban components on land surface temperature of Istanbul by using remote sensing indices. Environmental Monitoring and Assessment, 186(2), 859-872. https://doi.org/10.1007/s10661-013-3427-5

Balçık, F. B., \& Ergene, E. M. (2017). YER YÜZEY SICAKLIĞININ TERMAL UZAKTAN ALGILAMA VERILERİ İLE BELIRLENMESI : İSTANBUL ÖRNEĞİ. In TUFUAB 2017 (pp. 105-110).

Benediktsson, J. A., Swain, P. H., \& Ersoy, O. K. (1990). Neural Network Approaches Versus Statistical Methods In Classification Of Multisource Remote Sensing Data. IEEE Transactions on Geoscience and Remote Sensing, 28(4), 540-552. https://doi.org/10.1109/TGRS.1990.572944

Cicek, I., Yilmaz, E., Turkoglu, N., \& Caliskan, O. (2013). Ankara şehrinde yüzey sıcaklıklarının arazi örtüsüne göre mevsimsel değişimi. International Journal of Human Sciences, 10(1), 621-640. 
Duan, S.-B., Li, Z.-L., Wang, C., Zhang, S., Tang, B.-H., Leng, P., \& Gao, M.-F. (2018). Landsurface temperature retrieval from Landsat 8 single-channel thermal infrared data in combination with NCEP reanalysis data and ASTER GED product. International Journal of Remote Sensing, 00(00), 1-16. https://doi.org/10.1080/01431161.2018.14605 13

Duman Yüksel, Ü., \& Yılmaz, O. (2008). Ankara Kentinde Kentsel Is1 Adası Etkisinin Yaz Aylarında Uzaktan Algilama ve Meteorolojik Gözlemlere Dayalı Olarak Saptanması ve Değerlendirilmesi. Gazi Üniv. Müh. Mim. Fak. Der., 23(4), 937-952.

Gillespie, A., Rokugawa, S., Matsunaga, T., Steven Cothern, J., Hook, S., \& Kahle, A. B. (1998). A temperature and emissivity separation algorithm for advanced spaceborne thermal emission and reflection radiometer (ASTER) images. IEEE Transactions on Geoscience and Remote Sensing, 36(4), 1113-1126. https://doi.org/10.1109/36.700995

Guo, Z., Wang, S. D., Cheng, M. M., \& Shu, Y. (2012). Assess the effect of different degrees of urbanization on land surface temperature using remote sensing images. Procedia Environmental Sciences, 13(2011), 935-942. https://doi.org/10.1016/j.proenv.2012.01.087

Jiang, Y., Fu, P., Weng, Q., Baghdadi, N., \& Thenkabail, P. S. (2001). Assessing the Impacts of Urbanization-Associated Land Use/Cover Change on Land Surface Temperature and Surface Moisture: A Case Study in the Midwestern United States. Remote Sens, 7, 4880-4898. https://doi.org/10.3390/rs70404880

Jiménez-Muñoz, J. C., \& Sobrino, J. A. (2003). A generalized single-channel method for retrieving land surface temperature from remote sensing data. Journal of Geophysical Research, 109(April), 8112. https://doi.org/10.1029/2004JD004804

Kaya, S., Basar, U. G., Karaca, M., \& Seker, D. Z. (2012). Assessment of Urban Heat Islands Using Remotely Sensed Data. Ekoloji, 21(84), 107-113. https://doi.org/10.5053/ekoloji.2012.8412

Li, J., Song, C., Cao, L., Zhu, F., Meng, X., \& Wu, J. (2011). Impacts of landscape structure on surface urban heat islands: A case study of Shanghai, China. Remote Sensing of Environment, 115(12), 3249-3263. https://doi.org/10.1016/j.rse.2011.07.008

Liu, L., \& Zhang, Y. (2011). Urban Heat Island Analysis Using the Landsat TM Data and
ASTER Data: A Case Study in Hong Kong. Remote Sensing, 3(12), 1535-1552. https://doi.org/10.3390/rs3071535

Moyano, M., Garcia, M., Palacios-Orueta, A., Tornos, L., Fisher, J., Fernández, N., ... Juana, L. (2018). Vegetation Water Use Based on a Thermal and Optical Remote Sensing Model in the Mediterranean Region of Doñana. Remote Sensing, 10(7), 1105. https://doi.org/10.3390/rs 10071105

Onishi, A., Cao, X., Ito, T., Shi, F., \& Imura, H. (2010). Evaluating the potential for urban heat-island mitigation by greening parking lots. Urban Forestry and Urban Greening, 9(4), 323-332. https://doi.org/10.1016/j.ufug.2010.06.002

Qian, L. X., Cui, H. S., \& Jie, C. (2006). Impacts of land use and cover change on land surface temperature in the Zhujiang Delta. Pedosphere, 16(200523), 681-689.

Qin, Z., \& Karnieli, A. (1999). Progress in the remote sensing of land surface temperature and ground emissivity using NOAA-AVHRR data. International Journal of Remote Sensing, 20(12), 2367-2393. https://doi.org/10.1080/014311699212074

Qin, Z., Karnieli, A., \& Berliner, P. (2001). A monowindow algorithm for retrieving land surface temperature from Landsat TM data and its application to the Israel-Egypt border region. International Journal of Remote Sensing, 22(18), 3719-3746. https://doi.org/10.1080/01431160010006971

Şekertekin, A., Kutoğlu, Ş. H., Kaya, Ş., \& Marangoz, A. M. (2015). Uydu Verileri ile Arazi Örtüsündeki Yer Yüzey Sıcaklığ1 Değişimlerinin Analizi: Zonguldak Örneği, Türkiye. In 15. Türkiye Harita Bilimsel ve Teknik Kurultayı.

Sekertekin, A., Kutoglu, S. H., Marangoz, A. M., \& Kaya, S. (2016). The Surface Heat Island Effect of Urbanization: Spatial-Temporal Analysis. In 4th International Geography Symposium (pp. 80-87).

Sekertekin, A., Kutoglu, S. H. S. H. akan, \& Kaya, S. (2016). Evaluation of spatio-temporal variability in Land Surface Temperature: A case study of Zonguldak, Turkey. Environmental Monitoring and Assessment, 188(1), 30. https://doi.org/10.1007/s10661015-5032-2

Şensoy, S., Shahin, L., Yılmaz, E., Türkoğlu, N., Çiçek, İ., Darende, V., \& Yazıcı, B. (2017). Antalya Yüzey Isı Adası Özelliklerinin Uydu Verileri ile Analizi. In III. Meteorolojik 
Uzaktan Algilama Sempozyumu (pp. 133146).

Shen, H., Huang, L., Zhang, L., Wu, P., \& Zeng, C. (2016). Long-term and fine-scale satellite monitoring of the urban heat island effect by the fusion of multi-temporal and multi-sensor remote sensed data: A 26-year case study of the city of Wuhan in China. Remote Sensing of Environment, 172, 109-125. https://doi.org/10.1016/j.rse.2015.11.005

Sobrino, J. A., Jimenez-Muoz, J. C., Soria, G., Romaguera, M., Guanter, L., Moreno, J., ... Martinez, P. (2008). Land Surface Emissivity Retrieval From Different VNIR and TIR Sensors. IEEE Transactions on Geoscience and Remote Sensing, 46(2), 316-327. https://doi.org/10.1109/TGRS.2007.904834

Sobrino, J. A., Li, Z., Stoll, M. P., \& Becker, F. (1996). Multi-channel and multi-angle algorithms for estimating sea and land surface temperature with ATSR data. International Journal of Remote Sensing, 17(September 2012), 2089-2114. https://doi.org/10.1080/01431169608948760

Van de Griend, A. A., \& Owe, M. (1993). On the relationship between thermal emissivity and the normalized difference vegetation index for natural surfaces. International Journal of Remote Sensing, 14(6), 1119-1131. https://doi.org/10.1080/01431169308904400

Xiao, H., \& Weng, Q. (2007). The impact of land use and land cover changes on land surface temperature in a karst area of China. Journal of Environmental Management, 85, 245-257. https://doi.org/10.1016/j.jenvman.2006.07.01 6 